\title{
Clinical Characteristics and Precipitating Factors of Adolescent Suicide Attempters Admitted for Psychiatric Inpatient Care in South Korea
}

\author{
Subin Park', Jae-Won Kim², Bung-Nyun Kim², Jeong-Hoon Bae ${ }^{3}$, \\ Min-Sup Shin ${ }^{2}$, Hee-Jeong $\mathrm{Yoo}^{4}$, and Soo-Churl $\mathrm{Cho}^{2} \bowtie$ \\ ${ }^{1}$ Department of Psychiatry, Seoul National Hospital, Seoul, Republic of Korea \\ 2Division of Child and Adolescent Psychiatry, Department of Psychiatry, Seoul National University Hospital, Seoul, Republic of Korea \\ ${ }^{3}$ Department of Psychiatry, Bongseng Memorial Hospital, Busan, Republic of Korea \\ ${ }^{4}$ Department of Neuropsychiatry, Seoul National University Bundang Hospital, Seongnam, Republic of Korea
}

Objective We aimed to examine the rates, correlates, methods, and precipitating factors of suicide attempts among adolescent patients admitted for psychiatric inpatient care from 1999 to 2010 in a university hospital in Korea.

Methods The subjects consisted of 728 patients who were admitted for psychiatric inpatient care in a university hospital over a 12 -year period and who were aged 10-19 years at the time of admission. We retrospectively investigated the information on suicidal behaviors and other clinical information by reviewing the subjects' electronic medical records. Whether these patients had completed their suicide on 31 December 2010 was determined by a link to the database of the National Statistical Office.

Results Among 728 subjects, $21.7 \%$ had suicidal ideation at admission, and $10.7 \%$ admitted for suicidal attempts. Female gender, divorced/widowed parents, and the presence of mood disorders were associated with a significantly increased likelihood of suicide attempts. Most common method of suicide attempts was cutting, and most common reason for suicide attempts was relationship problems within the primary support group. A diagnosis of schizophrenia was associated with increased risk of death by suicide after discharge.

Conclusion These results highlight the role of specific psychosocial factor (e.g., relational problems) and psychiatric disorders (e.g., mood disorders) in the suicide attempts of Korean adolescents, and the need for effective prevention strategies for adolescents at risk for suicide.

Psychiatry Investig 2015;12(1):29-36

Key Words Suicide, Risk factors, Adolescents.

\section{INTRODUCTION}

Adolescent suicide, the third leading cause of death among youth 15 to 19 years old, is a major public health concern. ${ }^{1,2} \mathrm{~A}$ previous suicide attempt is well-known risk factor for death by suicide. ${ }^{3-5}$ The concern about suicide attempts is heightened by their association with increased psychological impairment, ${ }^{6-8}$

Received: October 11, 2013 Revised: December 14, 2013

Accepted: December 23, 2013 Available online: January 12, 2015

$\triangle$ Correspondence: Soo-Churl Cho, MD, PhD

Division of Child and Adolescent Psychiatry, Department of Psychiatry, Seoul National University College of Medicine, 101 Daehak-ro, Jongno-gu, Seoul 110-744, Republic of Korea

Tel: +82-2-2072-3648, Fax: +82-2-747-2471, E-mail: soochurl@snu.ac.kr

(a) This is an Open Access article distributed under the terms of the Creative Commons Attribution Non-Commercial License (http://creativecommons.org/licenses/bync/3.0) which permits unrestricted non-commercial use, distribution, and reproduction in any medium, provided the original work is properly cited. death by suicide, and potential cost to emergency departments and other urgent care facilities. ${ }^{9}$ Studies on adolescent suicide attempts are largely based on analyses of individual risk factors, often focused on mental health symptoms. Risk factors for adolescent suicide attempts include general mental health problems, ${ }^{10}$ substance abuse, ${ }^{11}$ low self-esteem, and impulsivity. ${ }^{12}$ From a psychosocial perspective, suicide attempts among adolescents have been associated with problems in family communication or problem solving ${ }^{13,14}$ and lower parental monitoring, ${ }^{13,14}$ death or previous suicide attempts by family members or friends, ${ }^{5,15-19}$ and interpersonal problems. ${ }^{20-24}$

In comparison to the abundant information on adolescent suicide attempts in Western countries, there is a paucity of data on risk factors for and characteristics of suicide attempts among adolescents in Asia. ${ }^{24-27}$ This omission is particularly significant for Koreans because suicide rates have increased 
rapidly and steadily in recent years, particularly among adolescents, in Korea: while in 2000, on average, 6.4 suicides per 100,000 adolescents aged 10-24 years were observed, in 2010 this rate was 9.4 suicides per 100,000 individuals, and the Korea's ranking of adolescent suicide rates climbed from 18th to 5 th in the Organization for Economic Cooperation and Development (OECD) countries over the past ten years. These findings are contrary to a decreasing trend of suicide mortality in adolescents of other OECD countries: while in 2000, on average across all OECD countries, 7.7 suicides per 100,000 adolescents aged 10-24 years were observed, in 2010 this rate was 6.5 suicides per 100,000 individuals. ${ }^{28}$

The purpose of this article is to present the first descriptive data regarding suicide attempts within a Korean adolescent sample. Because suicide attempts are common among adolescents with mental health problems, ${ }^{5}$ we examined the rates, correlates, methods, and precipitating factors of suicide attempts among adolescent patients admitted to a 20-bed child and adolescent psychiatric ward from 1999 to 2010 in a university hospital located in Seoul, Korea. Our psychiatric ward is one of two closed psychiatric ward exclusively for child and adolescent patients in Korea. The patients admitted in this ward have various emotional and behavioral symptoms as well as psychotic symptoms, severe enough for their admission to the closed ward. We also investigated the suicide mortality rates of these patients over the study period using the database of the National Statistical Office (NSO), to which all deaths in Korea are reported by a document of death notice containing the cause of death.

\section{METHODS}

\section{Subjects and procedures}

The subjects consisted of all patients who were admitted for psychiatric inpatient care in a national university hospital over a 12-year period (from January 1999 to December 2010) and who were aged 10-19 years at the time of admission. The 12year period of recruitment was chosen because electronic medical records have been available in the hospital since 1999, and we launched this study in January 2011. The average length of stay is 60.1 (SD 33.6) days6, the number of admission of each patient ranged from 1 to 6 (mean 1.4, SD 1.0), and the rates of recurrent admission (admission more than two times during 12 -years of period) were $27 \%$. For patients who had recurrent admission, medical records of each admission were all reviewed.

A board-certified child and adolescent psychiatrist reviewed the subjects' electronic medical records and determined whether the patients had suicidal ideation at admission or were admitted for suicide attempts. This information had been re- corded in the admission notes. A suicide attempt was defined as "an act with nonfatal outcome, in which an individual deliberately initiates a noninhabitual behavior that, without intervention form others, will cause self-harm, or deliberately ingests a substance in excess of the prescribed or generally recognized therapeutic dosage, and which is aimed at realizing changes which the subject desired via the actual or expected physical consequences". 29 For patients with suicide attempts, the method and precipitating factors of the suicide attempt were investigated. Socio-demographic and clinical characteristics as well as family-related factors (socio-economic status and family history of suicide) of the subjects were obtained by a child and adolescent psychiatry fellow through a retrospective chart review. The IQ had been measured by a psychologist using the Korean Educational Development Institute Wechsler Intelligence Scale for Children-Revised (KEDI-WISC-R). ${ }^{30}$ Family history of suicide had been obtained from the parent's report. The study was approved by the institutional review board (IRB) for human subjects at the Seoul National University College of Medicine.

\section{Instruments}

\section{Psychiatric diagnosis}

The medical record requirements of the participating hospital included one primary diagnosis and several auxiliary diagnoses based on the of the International Classification of Disease, 10th edition (ICD-10) $)^{31}$ coding in a discharge summary, which had been recorded by an attending board-certified psychiatrist after close inpatient observation, neuropsychological test, and clinical interview. The diagnosis of patients with multiple psychiatric disorders was made according to the primary ICD-10 diagnosis provided in the electronic medical records. For the purposes of the present study, these diagnoses were collapsed into eight diagnostic groups: organic mental disorders (F10-F19), psychotic disorders (F20-F29), affective disorders (F30-F33), neurotic disorders (F40-F48), disruptive behavioral disorders (F90-F92), mental retardation (F70-F79), eating disorders (F50), and Tourette's disorder (F95.2).

\section{Method of suicide}

Suicide methods were classified according to the international self-harm section (X60-X84) of the ICD-10 codes $^{31}$ : self-poisoning (X60-X69), hanging (X70), drowning (X71), firearms (X72-X74), burning (X75-X77), self-harm by sharp object (X78), self-harm by blunt objects (X79), jumping from a high place (X80), and others (X81-X84). For patients who used two (or more) methods of suicide (i.e., subjects who jumped from a height after drug intoxication), both methods were counted separately. 


\section{Precipitating factor of suicide}

The reviewing psychiatrist determined the precipitating factors for suicide attempt according to the International Classification of External Causes of Injury (ICECI) system 32 based on the description about suicide causes and suicide-related events in the medical records. The ICECI classification of precipitating factors is as follows: 1) conflict in relationship with family member, partner, or friend, 2) death of a relative, partner, or friend, 3) physical problem, 4) psychological/psychiatric condition, 5) income-related/financial problem, 6) abuse, 7) legal system encounters, 8) other specified proximal risk factors, and 9) unspecified proximal risk factor. Among several precipitating factors of suicide attempt, the most recent crisis that led to the self-harm, which corresponds to the definition of 'proximal risk factor' of the ICECI, was considered as a precipitating factor in this study. According to this definition, for example, in case of a girl who had suffered from peer relationship problems over 1 year prior and was affected by psychotic symptoms recently and attempted suicide, the precipitating factor would not be peer relationship problems but rather psychotic symptoms. In the case of suicide attempters with multiple precipitating factors, only one precipitating factor, the most temporally recent crisis that led to a suicide attempt, was selected.

\section{Suicide mortality}

Information about whether the patients had been alive at the time of December 31, 2010 was provided by linkage to the database of the NSO. The NSO data and hospital records were matched using the unique national identification number assigned to all Korean citizens. Data were censored either on date of death or on 31 December 2010. Person-years were calculated for each patient. For those dead, causes of death were also established through linkage to the database of the NSO. The causes of death were categorized based on the ICD-10 classification as follows: ${ }^{31}$ 1) infectious diseases, 2) neoplasms, 3) hematological diseases, 4) endocrine diseases, 5) mental and behavioral diseases, 6) nervous system diseases, 7) circulatory system diseases, 8) respiratory system diseases, 9) digestive system diseases, 10) skin and subcutaneous system diseases, 11) musculoskeletal system and connective tissue disease, 12) genitourinary system diseases, 13) diseases ill defined, and 14) traumatic episodes (injury, poisoning and certain other consequences of external causes). For traumatic episodes, external causes of death were also established as follows: 1) accident, 2) intentional self-harm, 3) assault, and 4) event of undetermined intent. Among these external causes of death, only death by intentional self-harm was considered as a completed suicide.

\section{Statistical analysis}

Descriptive statistics of sample characteristics and methods and precipitating factor of suicide were presented. We compared socio-demographic and clinical differences between adolescent inpatients with and without suicide attempts using an independent $t$-test for continuous variables and the chi-square or Fisher's exact tests for categorical variables. Multivariate logistic regression analysis was used to identify correlates of suicide attempts among adolescent inpatients. All statistical analyses were performed using SPSS (version 19.0; SPSS Inc., Chicago, IL, USA), with statistical significance defined as an alpha level $<0.05$.

The frequency of death by suicide was calculated as the number of deaths by suicide as a function of the person-years of follow-up. Standardized mortality ratios (SMRs) were calculated with PAMCOMP $1.41 .{ }^{33}$ SMRs compare the observed numbers of deaths with the expected numbers of deaths. The expected number of suicide-specific deaths was calculated from the suicide mortality rate in Korea for different age groups of males and females from 1999 to 2010.

\section{RESULTS}

A total of 728 patients (441 boys and 287 girls) were enrolled in the study. Of these patients, 553 (63.2\%) were males, and the remaining $322(36.8 \%)$ were females. The mean age was 14.6 (SD 1.7) years. Of the patients in the study, 22 percent ( $20.4 \%$ of boys and $23.7 \%$ of girls) had suicidal ideation at admission, and 10.7 percent of patients ( $8.2 \%$ of boys and $14.6 \%$ of girls) were admitted for suicidal attempts (Table 1 ).

Patients with suicide attempts were older and were more likely to be female and to have higher IQ, divorced or widowed parents, and mood disorder (Table 2). They were less likely to have disruptive behavioral disorders or mental retardation than were patients without suicide attempts (Table 3 ).

Multivariate analyses showed that female gender, divorced or widowed parents, and the presence of mood disorders were independently associated with suicide attempts upon presentation at the hospital (Table 4).

Common methods of suicide attempts were cutting and

Table 1. Prevalence of suicidal ideation, attempts, and family history of suicide among child and adolescent inpatients $(\mathrm{N}=728)$

\begin{tabular}{|c|c|c|c|c|c|}
\hline \multirow{2}{*}{ Characteristics } & Boys & Girls & Total & \multirow{2}{*}{$\chi^{2}$} & \multirow{2}{*}{$\mathrm{p}$} \\
\hline & $\mathrm{N}(\%)$ & $\mathrm{N}(\%)$ & $\mathrm{N}(\%)$ & & \\
\hline Suicidal ideation & & & & 1.1 & 0.293 \\
\hline Yes & $90(20.4)$ & $68(23.7)$ & $158(21.7)$ & & \\
\hline No & $351(79.6)$ & $219(76.3)$ & $570(78.3)$ & & \\
\hline Suicidal attempt & & & & 7.61 & 0.006 \\
\hline Yes & $36(8.2)$ & $42(14.6)$ & $78(10.7)$ & & \\
\hline No & 405 (91.8) & $245(85.4)$ & $650(89.3)$ & & \\
\hline
\end{tabular}


jumping for boys $(n=12,33.3 \%$ for each) and cutting $(n=25$, $59.5 \%)$ and drug intoxication $(n=10,27.8 \%)$ for girls. Jumping was more common as suicide methods for boys than for girls ( $\mathrm{n}=12,33.3 \%$ vs. $\mathrm{n}=5,12.2 \%$ ), and cutting was more common for girls than for boys ( $n=25,59.5 \%$ vs. $n=12,33.3 \%$ ) (Table 5).

Common precipitating factors for suicide attempts were bullying or collective social exclusion $(n=22,28.2 \%)$, parent-child relationship problems $(\mathrm{n}=12,28.2 \%)$, and psychotic symptoms $(\mathrm{n}=16,20.5 \%)$. Psychotic symptoms were more common as precipitating factors for boys than for girls $(n=12,33.3 \%$ vs. $\mathrm{n}=4,9.5 \%$ ), and depression was more common for girls than for boys ( $n=4,11.1 \%$ vs. $n=7,16.7 \%$ ) (Table 6 ).

Of the 728 patients, 7 (0.96\%, 3 females and 4 males) had died by December 2010. Among these 7 patients, 4 (0.55\%, 3 females and 1 male) had died from suicide, and remaining 3 had died from digestive system disease, mental and behavioral diseases, diseases ill defined. Based on SMRs adjusted for age and gender differences between the study population and the general Korean population, the suicide mortality rate of the adolescent psychiatric patients was 17.7 times (95\% CI 4.8-

Table 2. Differences between child and adolescent inpatients with and without suicide attempt

\begin{tabular}{|c|c|c|c|c|c|}
\hline & No suicide attempt $(\mathrm{N}=650)$ & Suicide attempt (N=78) & Total $(\mathrm{N}=728)$ & $\operatorname{tor} \chi^{2}$ & $\mathrm{p}$ \\
\hline Age, mean (SD) & $14.5(1.7)$ & $15.0(1.6)$ & $14.6(1.7)$ & -2.47 & 0.015 \\
\hline IQ, mean (SD) & $93.2(22.4)$ & $99.5(19.6)$ & $93.9(22.2)$ & -1.97 & 0.049 \\
\hline School status, N (\%) & & & & 0.21 & 0.646 \\
\hline While in school & $536(84.7)$ & $67(85.9)$ & $603(84.8)$ & & \\
\hline Dropping out of school & $97(15.3)$ & $11(14.1)$ & $108(15.2)$ & & \\
\hline Religion, N (\%) & & & & 1.52 & 0.218 \\
\hline No & $323(49.7)$ & $33(42.3)$ & $356(48.9)$ & & \\
\hline Yes & $327(50.3)$ & $45(57.7)$ & $372(51.1)$ & & \\
\hline Socio-economic status, N (\%) & & & & 3.03 & 0.22 \\
\hline High & $138(23.4)$ & $12(17.4)$ & $150(22.7)$ & & \\
\hline Middle & $331(56.0)$ & $37(53.6)$ & $368(55.8)$ & & \\
\hline Low & $122(20.6)$ & $20(29.0)$ & $142(21.5)$ & & \\
\hline Parental marital status, N (\%) & & & & 6.98 & 0.008 \\
\hline Married & $545(87.2)$ & $57(76.0)$ & $602(86.0)$ & & \\
\hline Divorced/widowed & $80(12.8)$ & $18(24.0)$ & $98(14.0)$ & & \\
\hline Family history of suicide, N (\%) & & & & 0.10 & 0.751 \\
\hline No & $255(93.1)$ & $69(92.0)$ & $333(92.5)$ & & \\
\hline Yes & $19(6.9)$ & $6(8.0)$ & $25(7.5)$ & & \\
\hline Psychotic symptoms, N (\%) & & & & 1.73 & 0.189 \\
\hline No & $448(69.7)$ & $48(62.3)$ & $496(68.9)$ & & \\
\hline Yes & $195(30.3)$ & $29(37.7)$ & $224(31.1)$ & & \\
\hline
\end{tabular}

Table 3. Comparison of diagnosis between child and adolescent inpatients with and without suicide attempt

\begin{tabular}{|c|c|c|c|c|c|}
\hline & No suicide attempt & Suicide attempt & Total & & \\
\hline & $(\mathrm{N}=650)$ & $(\mathrm{N}=78)$ & $(\mathrm{N}=728)$ & $\mathrm{t}$ & $\mathrm{p}$ \\
\hline Diagnosis, N (\%) & & & & 43.86 & $<0.001$ \\
\hline Organic mental disorder & $18(2.8)$ & $3(3.8)$ & $21(2.9)$ & 0.29 & 0.484 \\
\hline Psychotic disorder & $121(18.6)$ & $10(12.8)$ & $131(18.0)$ & 1.59 & 0.208 \\
\hline Mood disorder & $170(26.2)$ & $47(60.3)$ & $217(29.8)$ & 38.71 & $<0.001$ \\
\hline Neurotic disorder & $66(10.2)$ & $5(6.4)$ & $71(9.8)$ & 1.11 & 0.292 \\
\hline Disruptive behavioral disorder & $175(26.9)$ & $12(15.4)$ & $187(25.7)$ & 4.86 & 0.028 \\
\hline Eating disorder & $16(2.5)$ & $1(1.3)$ & $17(2.3)$ & 0.43 & $>0.99$ \\
\hline Tourette's disorder & $24(3.7)$ & $0(0.0)$ & $24(3.3)$ & 2.98 & 0.098 \\
\hline Mental retardation & $60(9.2)$ & $0(0.0)$ & $60(10.4)$ & 7.85 & 0.005 \\
\hline
\end{tabular}


45.4) higher than that of the general population. All 4 patients who completed their suicide had been diagnosed with schizophrenia at admission, and only one patient had been admitted for a suicide attempt.

\section{DISCUSSION}

Among adolescent psychiatric patients, approximately

Table 4. Correlates of suicide attempts among child and adolescent inpatients

\begin{tabular}{|c|c|c|}
\hline & $\mathrm{OR}^{*}(95 \% \mathrm{CI})$ & $\mathrm{p}$ \\
\hline Sex, female & $2.11(1.15-3.87)$ & 0.015 \\
\hline Widowed/divorced parents & $2.21(1.06-4.63)$ & 0.035 \\
\hline Organic mental disorders & $7.88(0.74-84.01)$ & 0.088 \\
\hline Psychotic disorder & $2.68(0.32-22.62)$ & 0.366 \\
\hline Mood disorder & $10.80(1.43-81.87)$ & 0.021 \\
\hline Disruptive behavioral disorder & $0.77(0.05-12.89)$ & 0.857 \\
\hline Other diagnosis $^{\dagger}$ & $2.19(0.26-18.66)$ & 0.473 \\
\hline Neurotic disorder & ref & \\
\hline
\end{tabular}

*backward stepwise regression method. Other independent variables in the multivariate models included age at admission and IQ (variables that showed group differences in the t-test or chi-square test at an alpha level $<0.1$ ), ${ }^{\dagger}$ other diagnoses include mental retardation, eating disorders, and Tourette's disorder twenty percent had suicidal ideation at admission, and 10.7 percent attempted suicide prior to hospitalization. Female gender, having a divorced or widowed parent, and the presence of mood disorder were associated with a significantly increased likelihood of suicide attempt upon presentation at the hospital. Cutting was the most common method of attempted suicide, and relationship problems with the primary support group were frequent precipitating factors for suicide.

Previous studies have reported that the prevalence rates of suicide attempts are two to three times higher in females than in males, ${ }^{34}$ although males have higher rates of death by suicide in adolescence and adulthood. ${ }^{34,35}$ We also found that suicide attempts were more common in girls than in boys. Consistent with previous studies conducted in adolescent psychiatric inpatients, ${ }^{13,14}$ suicide attempters were more likely to have a divorced or widowed parent. Adolescents from non-intact family are less likely to have and maintain healthy relationships with their parents, and these parent-child relationship problems are common precipitating factors for suicide attempts. ${ }^{5,15-17}$

Consistent with previous studies, ${ }^{1,15,17}$ we found that mood disorders had a substantial impact on the risks of suicide attempts in adolescent psychiatric patients. Longitudinal studies also support associations between mood disorders and attempted or completed suicide. ${ }^{36}$

Cutting, jumping, and drug intoxication were the most

Table 5. Methods of suicide attempts among child and adolescent inpatients

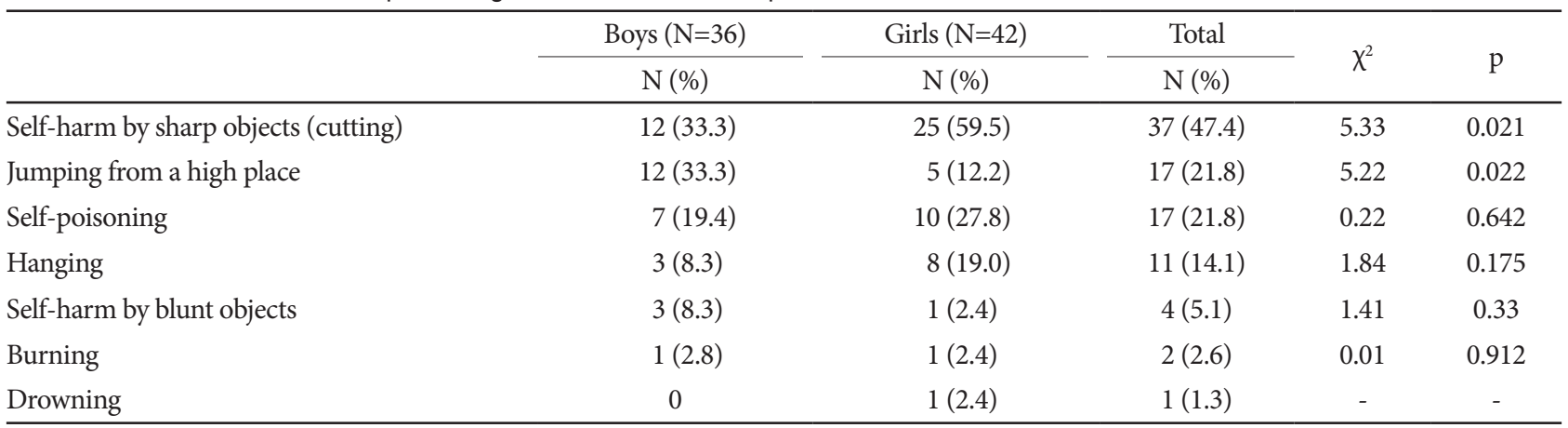

Table 6. Precipitating factors for suicide attempts among child and adolescent inpatients

\begin{tabular}{|c|c|c|c|c|c|c|}
\hline \multirow{2}{*}{ ICECI classification } & \multirow{2}{*}{ Description } & \multirow{2}{*}{$\frac{\text { Boys }(\mathrm{N}=36)}{\mathrm{N}(\%)}$} & \multirow{2}{*}{$\frac{\text { Girls }(\mathrm{N}=42)}{\mathrm{N}(\%)}$} & \multirow{2}{*}{$\begin{array}{r}\text { Total } \\
\mathrm{N}(\%) \\
\end{array}$} & \multirow{2}{*}{$\chi^{2}$} & \multirow{2}{*}{$\mathrm{p}$} \\
\hline & & & & & & \\
\hline \multirow{2}{*}{$\begin{array}{l}\text { Conflict in relationship with family } \\
\text { member, partner, or friend }\end{array}$} & Bullying or collective social exclusion & $9(25.0)$ & $13(31.0)$ & $22(28.2)$ & 0.34 & 0.560 \\
\hline & Parent-child relationship problems & $10(27.8)$ & $12(28.6)$ & $22(28.2)$ & 0.01 & 0.938 \\
\hline \multirow[t]{2}{*}{ Psychological/psychiatric condition } & Psychotic symptoms & $12(33.3)$ & $4(9.5)$ & $16(20.5)$ & 6.74 & 0.009 \\
\hline & Depression & $4(11.1)$ & $7(16.7)$ & $12(15.4)$ & 0.5 & 0.482 \\
\hline Abuse & Sexual abuse & 0 & $3(7.1)$ & $3(3.8)$ & - & - \\
\hline Death of a relative, partner, or friend & Death of close relative & $1(2.8)$ & 0 & $1(1.3)$ & - & - \\
\hline Other specified proximal risk factor & Academic failure & 0 & $3(7.1)$ & $3(3.8)$ & - & - \\
\hline
\end{tabular}

ICECI: International Classification of External Causes of Injury 
common methods of attempted suicide by adolescents. Previous research has found that intentional overdose and wrist cutting are the most common methods of attempting suicide in Western adolescent psychiatric inpatients. ${ }^{37,38}$ Jumping from heights is the second most common method for suicide attempters in our study, although attempted suicide by jumping is a relatively uncommon method in most Western countries. These differences in methods of suicide between countries may be related to the methods' availability. In Korea, drugs are difficult to access by adolescents. Thus, many adolescents living in high-rise buildings choose to jump from heights, a readily available method. When we compared the methods of suicide attempt by gender, boys were more likely to use jumping, while girls were more likely to do it by cutting. The high lethality of jumping, a suicide method commonly used by boys, contributes to the higher suicide mortality in boys, although girls typically have a higher rate of suicide attempts than boys do. ${ }^{34}$

Our findings of relationship problems with the primary support group, such as parents and friends, as the most commonly reported central precipitating factor for suicide attempts among both males and females should guide interventions designed to address these problems. Several previous studies have found that relational problems are central to the development toward a suicide attempt in adolescent psychiatric patients. ${ }^{14,39}$ Negative parent-child relationships have a central and enduring role in the suicidal behavior of adolescents and young adults. ${ }^{15,40}$ In our study, peer relationship problems (22.2\%) were reported as precipitating factors as often as relationship problems with parents (22.8\%) and mainly included bullying or collective social exclusion. Victimization in school by peers has an association to suicide that exceeds the risks of age, race, gender, and even depressive symptoms. ${ }^{41}$ Fear of social exclusion from the peer group may be particularly strong in a collective society such as Korea. ${ }^{42}$ Despite the high frequency of mood disorder in suicide attempters (29.8\%), depression was reported as a precipitating factor only in a $15.4 \%$ of suicide attempters. This result may be due that we selected only one precipitating factor in each patient. Many depressive patients also had another precipitating factor such as a conflict in relationship with parent or friend, and such event was often judged as the most temporally recent crisis that led to a suicide attempt in many cases. When we compared the precipitating factor by gender, predominant psychotic symptoms for boys and predominant depression for girls seem to be consistent with other studies that examined factors associated with suicide attempts among adolescents. ${ }^{10}$ In our study, other problems, such as sexual abuse and academic failure, were identified as precipitating factors, but only for females.

In our clinical sample, $0.55 \%$ of the adolescents had completed their suicide by December 2010, a number 15 times higher than expected in the general population of Korean adolescents. Although this conclusion is based on only four cases, this figure is almost identical to those reported in previous Swedish, ${ }^{43}$ Finnish, ${ }^{44}$ and US studies. ${ }^{45}$ The four adolescents who committed suicide were suffering from schizophrenia, which is a commonly reported risk factor for suicide. ${ }^{43,56,47}$ Suicide by schizophrenic patients often occurs early in the course of the disease. ${ }^{48-51}$ Therefore, adolescents with schizophrenia are particularly at risk. In our study, only one patient was a former suicide attempter, suggesting that adolescents with schizophrenia merit clinical attention to safeguard against suicide risk even if they have no history of previous suicide attempts. It should be noted that NSO data may underestimate the number of deaths due to suicide because some suicides may have been classified as "undetermined" deaths. ${ }^{52,53}$ Among seven deaths in our patients, there were two undetermined deathsdeath from diseases ill-defined and death from mental and behavioral disease.

The present study has several limitations. First, the study employed a retrospective methodological design. Because data were gathered from electronic medical charts rather than faceto-face interviews, some important information such as severity of the suicide attempt or number of previous attempt was not available in many patients, so was not included as a correlate variable in this study. Moreover, chart review was not done by the attending psychiatric resident or fellow who had recorded medical chart, but by another psychiatrist. Second, because the study was conducted in a single university hospital, the findings may not be representative of all psychiatric adolescent inpatients in Korea. Third, we could not examine the effect of comorbid psychiatric conditions on suicide attempts because only a primary diagnosis was considered in this study. Prior research has suggested that patients with comorbid conditions are at elevated risk of suicide. ${ }^{5,50,54}$ Finally, the very low number of deaths by suicide limited the statistical analysis of risk factors for completed suicide. Although suicide was more common in our psychiatric population than in the general population, large sample sizes are needed to study rare outcomes. Thus, additional prospective, controlled studies in many hospitals nationwide are required.

Despite these limitations, the present observations highlight the role of specific psychosocial factor (e.g., relational problems) and psychiatric disorders (e.g., mood disorders) in the suicide attempts of Korean adolescents. In terms of clinical implications, our results indicate that preventive work should be directed toward solving relational issues, both at home and at school, and active treatment of mood or psychotic disorders. 


\section{Acknowledgments}

This study was supported by grant 04-2011-0620 from the Seoul National University Hospital Research Fund and by the National Research Foundation of Korea (NRF Grant funded by the Korean Govrnment (MSIP) (No. 2014R1A1A3049818).

\section{REFERENCES}

1. Spirito A, Esposito-Smythers C. Attempted and completed suicide in adolescence. Annu Rev Clin Psychol 2006;2:237-266.

2. WHO. Suicide Prevention (SUPRE) Information. Geneva: World Health Organization; 2012.

3. Owens D, Horrocks J, House A. Fatal and non-fatal repetition of selfharm. Systematic review. Br J Psychiatry 2002;181:193-199.

4. Suominen K, Isometsa E, Suokas J, Haukka J, Achte K, Lonnqvist J. Completed suicide after a suicide attempt: a 37-year follow-up study. Am J Psychiatry 2004;161:562-563.

5. Gould MS, Greenberg T, Velting DM, Shaffer D. Youth suicide risk and preventive interventions: a review of the past 10 years. J Am Acad Child Adolesc Psychiatry 2003;42:386-405.

6. Joiner TE. Why People Die by Suicide. Cambridge: Harvard University Press; 2005.

7. Joiner TE Jr, Steer RA, Brown G, Beck AT, Pettit JW, Rudd MD. Worstpoint suicidal plans: a dimension of suicidality predictive of past suicide attempts and eventual death by suicide. Behav Res Ther 2003;41: 1469-1480.

8. Goldston DB. Measuring Suicidal Behavior and Risk in Children and Adolescents. Washington, DC: American Psychological Association; 2003.

9. Prinstein MJ. Introduction to the special section on suicide and nonsuicidal self-injury: a review of unique challenges and important directions for self-injury science. J Consult Clin Psychol 2008;76:1-8.

10. Evans E, Hawton K, Rodham K. Factors associated with suicidal phenomena in adolescents: a systematic review of population-based studies. Clin Psychol Rev 2004;24:957-979.

11. De Leo D, Heller TS. Who are the kids who self-harm? An Australian self-report school survey. Med J Aust 2004;181:140-144.

12. Klonsky ED, May A. Rethinking impulsivity in suicide. Suicide Life Threat Behav 2010;40:612-619.

13. DiFilippo JM, Overhosler JC. Suicidal ideation in adolescent psychiatric inpatients as associated with depression and attachment relationships. J Clin Child Psychol 2000;29:156-166.

14. Prinstein MJ, Boergers J, Spirito A, Little TD, Grapentine WL. Peer functioning, family dysfunction, and psychological symptoms in a risk factor model for adolescent inpatients' suicidal ideation severity. J Clin Child Psychol 2000;29:392-405.

15. Beautrais AL. Life course factors associated with suicidal behaviors in young people. Am Behav Sci 2003;46:1137-1156.

16. Gould MS, Kramer RA. Youth suicide prevention. Suicide Life Threat Behav 2001;(31 Suppl):6-31.

17. Pfeffer CR. Diagnosis of childhood and adolescent suicidal behavior: unmet needs for suicide prevention. Biol Psychiatry 2001;49:1055-1061.

18. Pompili M, Mancinelli I, Girardi P, Ruberto A, Tatarelli R. Childhood suicide: a major issue in pediatric health care. Issues Compr Pediatr Nurs 2005;28:63-68.

19. Brent DA, Mann JJ. Family genetic studies, suicide, and suicidal behavior. Am J Med Genet C Semin Med Genet 2005;133C:13-24.

20. Perkins DF, Hartless G. An ecological risk-factor examination of suicide ideation and behavior of adolescents. J Adolesc Res 2002;17:3-26.

21. Johnson JG, Cohen P, Gould MS, Kasen S, Brown J, Brook JS. Childhood adversities, interpersonal difficulties, and risk for suicide attempts during late adolescence and early adulthood. Arch Gen Psychiatry 2002;59:741-749.

22. Bearman PS, Moody J. Suicide and friendships among American adolescents. Am J Public Health 2004;94:89-95.
23. Hur JW, Kim WJ, Kim YK. The mediating effect of psychosocial factors on suicidal probability among adolescents. Arch Suicide Res 2011; 15:327-336.

24. Wai BH, Hong C, Heok KE. Suicidal behavior among young people in Singapore. Gen Hosp Psychiatry 1999;21:128-133.

25. Wong JP, Stewart SM, Ho SY, Rao U, Lam TH. Exposure to suicide and suicidal behaviors among Hong Kong adolescents. Soc Sci Med 2005; 61:591-599.

26. Cui S, Cheng Y, Xu Z, Chen D, Wang Y. Peer relationships and suicide ideation and attempts among Chinese adolescents. Child Care Health Dev 2011;37:692-702.

27. Shek DT, Yu L. Self-harm and suicidal behaviors in Hong Kong adolescents: prevalence and psychosocial correlates. ScientificWorldJournal 2012;2012:932540.

28. OECD: OECD Health Data. Paris: OECD; 2011.

29. Platt S, Bille-Brahe U, Kerkhof A, Schmidtke A, Bjerke T, Crepet P, et al. Parasuicide in Europe: the WHO/EURO multicentre study on parasuicide. I. Introduction and preliminary analysis for 1989. Acta Psychiatr Scand 1992;85:97-104.

30. Park KS, Yoon JY, Park HJ, Park HJ, Kwon KU. Development of KEDIWISC, Individual Intelligence Test for Korean Children. Seoul: Korean Educational Development Institute; 1996.

31. World Health Organization. International Statistical Classification of Diseases and Related Health Problems, 10th Revision. Geneva: WHO; 2010.

32. ICECI, Group CaM. Internatonal Classification of External Causes of Injuries (ICECI) Version 1.2. Amsterdam: Consumer Safety Institute and AIHW National Injury Surveillance Unit; 2004.

33. Taeger D, Sun Y, Keil U, Straif K. A stand-alone windows application for computing exact person-years, standardized mortality ratios and confidence intervals in epidemiological studies. Epidemiology 2000; 11:607-608.

34. Lewinsohn PM, Rohde P, Seeley JR, Baldwin CL. Gender differences in suicide attempts from adolescence to young adulthood. J Am Acad Child Adolesc Psychiatry 2001;40:427-434.

35. Cooper J, Kapur N, Webb R, Lawlor M, Guthrie E, Mackway-Jones K, et al. Suicide after deliberate self-harm: a 4-year cohort study. Am J Psychiatry 2005;162:297-303.

36. Mazza JJ, Catalano RF, Abbott RD, Haggerty KP. An examination of the validity of retrospective measures of suicide attempts in youth. J Adolesc Health 2011;49:532-537.

37. Brent DA. Correlates of the medical lethality of suicide attempts in children and adolescents. J Am Acad Child Adolesc Psychiatry 1987; 26:87-91.

38. Dieserud G, Gerhardsen RM, Van den Weghe H, Corbett K. Adolescent suicide attempts in Baerum, Norway, 1984-2006. Crisis 2010;31: 255-264.

39. Adams DM, Overholser JC, Lehnert KL. Perceived family functioning and adolescents suicidal behavior. J Am Acad Child Adolesc Psychiatry 1994;33:498-507.

40. Connor JJ, Rueter MA. Parent-child relationships as systems of support or risk for adolescent suicidality. J Fam Psychol 2006;20:143-155.

41. Kaminski JW, Fang X. Victimization by peers and adolescent suicide in three US samples. J Pediatr 2009;155:683-688.

42. Lee $\mathrm{CH}$. Personal and interpersonal correlates of bullying behaviors among Korean middle school students. J Interpers Violence 2010;25: 152-176.

43. Rydelius PA. Deaths among child and adolescent psychiatric patients. Acta Psychiatr Scand 1984;70:119-126.

44. Kotila L, Lonnqvist J. Adolescent suicide attempts 1973-1982 in the Helsinki area. Acta Psychiatr Scand 1987;76:346-354.

45. Pfeffer CR, Klerman GL, Hurt SW, Lesser M, Peskin JR, Siefker CA. Suicidal children grow up: demographic and clinical risk factors for adolescent suicide attempts. J Am Acad Child Adolesc Psychiatry 1991;30:609-616. 
46. Marttunen MJ, Aro HM, Henriksson MM, Lonnqvist JK. Mental disorders in adolescent suicide. DSM-III-R axes I and II diagnoses in suicides among 13- to 19-year-olds in Finland. Arch Gen Psychiatry 1991; 48:834-839.

47. Otto U. Suicidal acts by children and adolescents. A follow-up study. Acta Psychiatr Scand Suppl 1972;233:7-123.

48. Dutta R, Murray RM, Hotopf M, Allardyce J, Jones PB, Boydell J. Reassessing the long-term risk of suicide after a first episode of psychosis. Arch Gen Psychiatry 2010;67:1230-1237.

49. Rossau CD, Mortensen PB. Risk factors for suicide in patients with schizophrenia: nested case-control study. Br J Psychiatry 1997;171: 355-359.

50. Lui SY. Risk factors for deliberate self-harm and completed suicide in young Chinese people with schizophrenia. Aust N Z J Psychiatry 2009; 43:252-259.

51. Palmer BA, Pankratz VS, Bostwick JM. The lifetime risk of suicide in schizophrenia: a reexamination. Arch Gen Psychiatry 2005;62:247253.

52. Evenson RC, Cho DW, Holland R. Identifying psychiatric suicides for research purposes. J Clin Psychol 1988;44:1029-1032.

53. Marusic A, Roskar S, Zorko M. Undetermined deaths: are they suicides? Croat Med J 2003;44:550-552.

54. Foley DL, Goldston DB, Costello EJ, Angold A. Proximal psychiatric risk factors for suicidality in youth: the Great Smoky Mountains Study. Arch Gen Psychiatry 2006;63:1017-1024. 